\title{
HIPEREXPOSIÇÃO PESSOAL NAS REDES SOCIAIS E SEUS REFLEXOS NO DIREITO
}

\author{
Bruna Marangoni Brancaleone Costa ${ }^{1}$ \\ Irineu Francisco Barreto Junior ${ }^{2}$
}

\section{RESUMO}

Este artigo analisa os riscos da hiperexposição pessoal nas redes sociais, fenômeno contemporâneo inserido no contexto da Sociedade da Informação, e seus reflexos na área do Direito. Com o advento da internet e das redes sociais, tornou-se habitual que a maior parte dos cidadãos divulguem suas informações em redes sociais sem terem a devida dimensão do impacto que essa excessiva exposição possa provocar. A segurança na rede costuma ser negligenciada e a exposição exacerbada torna vulnerável a proteção da privacidade, tornado os indivíduos vulneráveis aos mecanismos de controle do Estado e do Mercado.

Palavras Chaves: Sociedade da Informação; Proteção de Dados Pessoais; Marco Civil da Internet; Rastros Digitais.

\section{HYPEREXPOSITION ON SOCIAL NETWORKS AND ITS LEGAL REFLECTIONS}

\section{ABSTRACT}

This article analyzes the risks of personal hyperexposure in social networks, a contemporary phenomenon inserted in the context of the Information Society, and its repercussions in the area of Law. With the advent of the internet and social networks, it has become customary for most citizens to disclose their information on social networks without having the right size of the impact that such overexposure can cause. Network security is often neglected and exacerbated exposure renders vulnerable to privacy protection, making individuals vulnerable to state and market control mechanisms.

Key Words: Information Society; Protection of Personal Data; Internet Brazilian Law; Digital Tracks.

\section{INTRODUÇÃO}

O presente artigo aborda a exposição excessiva da vida intima percebida nos últimos anos e decorrente da expansão em escala mundial da internet e do advento das redes sociais. Hodiernamente, a grande maioria dos cidadãos estão conectados às mídias sociais e, para

\footnotetext{
${ }^{1}$ Mestranda pelo Programa de Direito da Sociedade da Informação do Centro Universitário das Faculdades Metropolitanas Unidas - FMU-SP. Especialista latu sensu em Processo Civil com Ênfase em Direito Empresarial, pelo Complexo Educacional Damásio de Jesus. Advogada. São Paulo, Brasil. bruna@marangonibrancaleone.com.br.

2 Pós Doutorando em Sociologia pela Faculdade de Filosofia, Letras e Ciências Humanas (FFLCH), da Universidade de São Paulo - USP. Doutor em Ciências Sociais pela Pontifícia Universidade Católica de São Paulo - PUC-SP. Docente do Programa de Mestrado em Direito da Sociedade da Informação e do Curso de Direito da FMU-SP. Analista de Pesquisas da Fundação Seade - SP. São Paulo - SP, Brasil. neubarreto@hotmail.com.
} 
acessá-las, devem aceitar diversos termos impostos pelos aplicativos, dentre os quais a cessão de seus dados pessoais. A criação da World Wide Web, termo em inglês que significa teia ou rede mundial de computadores, também ficou conhecida como web ou www, trata-se de um sistema de documentos em hipermídia que são interligados e executados na Internet. Surgido em 1989, com a função de integrar informações, dentro das informações disponíveis na Internet, poderiam ser acessadas de forma mais simples e consistente em qualquer plataforma (World Wide Web, 2018).

A Internet desenvolveu-se com tanta velocidade que, ao transformar o convívio social e econômico, gerou uma série de novas oportunidades e riscos, ônus e bônus de sua existência (LIMA, 2016, p. 23). Na última década, foi possível observar a transformação da Internet na principal plataforma planetária de comunicação, entretenimentos, negócios, relacionamentos, aprendizagem e uma mudança na sociedade, pois hoje temos uma sociedade praticamente conectada. Como esclarece Martha Gabriel "esse cenário é deslumbrante e torna a Internet (com todas as suas ramificações e plataformas) o cérebro global coletivo, onipresente, onisciente e onipotente" (GABRIEL, 2018, p. 01). Permitindo um novo cenário com todas as possibilidades que o ser humano é capaz de chegar. Novos desafios e profundas transformações.

A Internet hoje tem mais de 800 mil websites e são criadas mais de mil homepages por dia (PINHEIRO, 2016, p. 69). Atualmente, grande parte dos websites da Internet está localizado nos Estados Unidos da América, todavia, o Brasil é um dos países que mais paga a conta dos backbones, por terem carência de "peering points". Informação é poder, como foi um dia a propriedade na terra (PINHEIRO, 2016, p. 70).

Acontece que toda essa permissão de ter toda a tecnologia num clique, desenvolveuse numa velocidade exacerbada, desafiando e pondo a prova, as novas habilidades dos cidadãos, pois o crescimento frenético ocorreu, mas a educação digital para a nova Era Digital não acompanhou no mesmo compasso. Segundo ainda Martha Gabriel.

Tecnologia e humanidade andam de mãos dadas desde o início da nossa história. O ser humano é uma tecnoespécie: criamos a tecnologia e somos transformados por elas, em um ciclo continuo que tem se retroalimentado durante todo o processo evolutivo da humanidade. Esse casamento tecno-humano, que na pré-história era com paus e pedras, culmina hoje com as tecnologias digitais, revolucionando o mundo e nos levando a uma nova era: Era Digital (GABRIEL, 2018, p. 07). 
A revolução tecnológica ocorrida nos meios de comunicação, desde meados da década de 1990, deu origem a uma nova era denominada como Sociedade da Informação. A sua principal característica é a geração e propagação de informações, advindas de qualquer lugar do mundo, em tempo quase que real e de forma inédita na história da tecnologia (BARRETO JUNIOR, p. 100-127.). Denota-se que a informação é o centro gravitacional desta nova era ou, em outras palavras, é possível afirmar que ela possui valor comercial.

Todavia, essa não foi e tampouco será a última das Revoluções, mas a Revolução Tecnológica a princípio, mostra-se como um mundo encantado e perfeito, não demonstrando que seu mau uso, pode gerar danos e inúmeras ameaças. Não valorizando a preciosidade que temos com nossos dados pessoais, pois se busca apenas a exposição do que se tem, ao invés da segurança do que se tem. O Direito Digital consiste na evolução do próprio Direito, abrangendo todos os princípios fundamentais e institutos que estão vigentes e são aplicados até hoje. No Direito Digital prevalecem os princípios em relação às regras, pois o ritmo de evolução tecnológica será sempre mais veloz que a da atividade legislativa (PINHEIRO, 2016, p. 78).

A objetivo deste artigo é compreender de forma mais acurada o perigo dos rastros digitais causados pela hiperexposição nas mídias sociais, assim como analisar os riscos e a prevenção da exposição com segurança. $\mathrm{O}$ artigo adota a vertente metodológica jurídicosociológica, que se propõe a "compreender o fenômeno jurídico no ambiente social mais amplo" (GUSTIN; DIAS, 20016, passim) ao analisar o direito como variável dependente da sociedade e trabalhar com as noções de eficiência, eficácia e efetividade das relações entre direito e sociedade.

\section{Os Dados Pessoais na Tecnologia vs. Realidade}

No ordenamento jurídico brasileiro a vida privada de qualquer pessoa natural é protegida como um Direito Fundamental, sendo irrenunciável. Entretanto o fornecimento dos dados pessoais, uma vez armazenados por terceiros, podem sofrer diversos danos, que ofenderia drasticamente o direito à privacidade de alguém.

Privacidade deriva de privatus, algo fora do Estado, pertencente apenas ao indivíduo e este é livre para o dispor. Esse direito nasceu para proteger o homem do Estado, que dantes 
não tinha garantia alguma da sua privacidade dentro do seu lar. Esse direito é tão inerente ao homem, que surgiu primeiramente na Carta Magna em 1215 pelo Rei João sem Terra. Pois se fosse garantido ao homem o direito à propriedade, este estava resguardado no seu lar e o Estado não poderia ir até este lesionar o direito dele. Daí surgiu o direito à privacidade, pois o homem que tivesse propriedade tinha guarda da privacidade no seu lar.

Já no Século XX, a intimidade e a privacidade foram reconhecidas como direitos fundamentais do homem, portando, direitos oriundos da personalidade. Esse direito fundamental foi reconhecido e proclamado pela ONU e passou a integrar a legislação de muitos países membros, todos que prezavam pela liberdade do homem. Em nosso pais, o direito à privacidade recebe proteção legal na Constituição Federal, no rol do Art. $5^{\circ}, \mathrm{X}$, que traz a seguinte redação: "são invioláveis a intimidade, a vida privada, a honra e a imagem das pessoas, assegurado o direito a indenização pelo dano material ou moral decorrente da sua violação". Já no Código Civil de 2002, no seu Art. 21 aduz que "a vida privada da pessoa natural é inviolável, e o juiz, a requerimento do interessado, adotará as providencias necessárias para impedir ou fazer cessar ato contrário a esta norma”.

O direito à privacidade, embora surgido da proteção à propriedade e à inviolabilidade do lar, posteriormente transmudado para inviolabilidade do domicilio, se revela pela intromissão não autorizada de terceiros na esfera pessoal do indivíduo (PAESANI, 2009, p. 159). Já o direito à privacidade engloba todos os direitos inerentes a pessoa. Mas, esses direitos fundamentais têm limitações. No entendimento da autora:

\footnotetext{
A intimidade esta afeta ao right to be alone, ou seja, o direito de estar só, no sentido de que todo o indivíduo tem o direito de estar só, no sentido de que todo o indivíduo tem o direito de reservar-se, de não ternar públicos aspectos da sua vida e de não permitir que terceiros tornem esses dados públicos, mesmo que esses sejam membros da família que vivam sob o mesmo teto (PAESANI L. M., 2009, p. 160).
}

O Direito Digital tem o desafio de equilibrar a difícil relação existente entre interesse comercial, privacidade, responsabilidade e anonimato, gerado pelos novos veículos de comunicação (PINHEIRO, 2016, p. 94). Toda essa equação, só tem fundamento se de um lado houver vigilância e de outro a punibilidade.

A Era Digital tem como natureza jurídica a Sociedade da Informação, esta por si só, gera mudanças que por muitos anos, não se via. Posto isso, o Direito nos países adeptos a Civil Law sofre com a realidade digital, pois para garantir o fundamento do Direito, por vezes 
as mudanças por costumes, vem de maneira súbita. O Direito da Personalidade fora fixado na Declaração Universal dos Direitos Humanos em 1948, bem como no Código Civil de 2002, assim como trazido na Constituição Federal vigente no seu Artigo $5^{\circ}$, inciso X, porém, o conceito de privacidade elencado por todos os diplomas legais, se modificou e vem evoluindo constantemente, para que possa englobar todas as mudanças que a sociedade vem sofrendo, principalmente ao desafio no que tange a privacidade na Sociedade da Informação. Para Patrícia Scarzelli:

\begin{abstract}
A necessidade de uma tutela jurídica da vida privada tornou-se ainda mais premente com o advento da era tecnológica e com as novas possibilidades abertas à invasão da intimidade. A tecnologia destina-se, em primeira análise, ao enriquecimento da personalidade humana, à ampliação da capacidade de domínio sobre a natureza, aprofundamento do conhecimento e disseminação da riqueza, revelando e promovendo novos rumos de acesso ao conforto. Seus efeitos, todavia, propagam-se das mais diversas e indesejadas formas. (SCARZELLI, 1997, p. 23)
\end{abstract}

O Direito à intimidade e à privacidade são direitos da nossa personalidade. Estão garantidos nos maiores diplomas legais. É proteção da pessoa, do ser, do modo de ser. A grande parte da sociedade, de maneira voluntária ou involuntária, muitas vezes por não ter ciência do que será feito com os dados por estes informado, passam seus dados pessoais para terceiros. Acontece que estes serão utilizados por terceiros e quase que na maioria das vezes, por terceiros totalmente desconhecido, e nesse passo, importante lembrarmos a lição de Carlos Alberto Bittar sobre os direitos da personalidade:

São prerrogativas de toda pessoa humana pela sua própria condição, referentes aos
seus atributos essenciais em suas emanações e prolongamentos, são direitos
absolutos, implicam num dever geral de abstenção para a sua defesa e salva- guarda,
são indisponíveis, intransmissíveis, irrenunciáveis e de difícil estimação pecuniária.
Outrossim, são inatos (originários), absolutos, extrapatrimoniais, imprescritíveis,
impenhoráveis, vitalícios, necessários e oponíveis erga omnes, segundo a melhor
doutrina e o artigo 11 do Código Civil (BITTAR, 2003, p. 11).

É evidente que para o direito à privacidade constitui um limite natural ao direito à informação que permitimos dar. Mas, haverá lesão se este por não consentir, for repassado. Todavia, muitos se expõe hoje em dia nas redes, esquecendo totalmente da segurança virtual.

Com toda o avanço que resta gerado pelo avanço da Era Digital por vezes a curiosidade para saber da vida alheia é mórbida, e as consequências podem ser de danos irreparáveis, imensuráveis e por vezes irreversíveis. A privacidade para Stefano Rodotá é uma coleta de informações, ainda esclarece que privacidade é o "direito a ser deixado só" 
(RODOTA, 2008, p. 24), o que acaba decaindo pela possibilidade de cada um controlar o uso das suas informações como queiram e lhe digam respeito. Esclarece ainda que:

As novas dimensões da coleta e do tratamento de informações provocaram a multiplicação de apelos à privacidade e, ao mesmo tempo, aumentaram a consciência da impossibilidade de confinar as novas questões que surgem dentro do quadro institucional tradicionalmente identificados por este conceito (RODOTA, 2008, p. 23).

O processo evolutivo do conceito da privacidade fez com que o seu conteúdo fosse preenchido pela garantia de isolamento e reserva do indivíduo em si. Dando a ele a possibilidade deste poder controlar o uso das suas informações. De acordo com Stefano Rodotá "na sociedade da informação tendem a prevalecer definições funcionais da privacidade que, de diversas formas, fazem referência à possibilidade de um sujeito conhecer, controlar, endereçar, interromper o fluxo das informações, a ele relacionadas" (ALMEIDA, TEIXEIRA, \& TEPEDINO, 2016, p. 255). Pois os dados pessoais resguardam aos indivíduos e ao todo grupo nele inserido. Ainda Stefano Rodotá aponta:

De sua tradicional definição como "direito a ser deixado só" passa-se, justamente pela influência da tecnologia dos computadores, àquela que constituirá um constante ponto de referência na discussão: "direito a controlar o uso que os outros façam das informações que me digam respeito". Em fase mais recente surge um outro tipo de definição, segundo a qual a privacidade se consubstancia no "direito do indivíduo de escolher aquilo que está disposto a revelar aos outros" (ALMEIDA, TEIXEIRA, \& TEPEDINO, 2016, p. 286).

Desafiador é estabelecer parâmetros razoáveis pois os dados pessoais que são capturados automaticamente são compartilhados. Na visão de Lipovetsky "temporalidade dominada pelo precário e pelo efêmero (...) uma primazia do aqui-agora. É uma dinâmica do hiper, com o qual o direito ainda analógico parece não conseguir lidar. (ALMEIDA, TEIXEIRA, \& TEPEDINO, 2016, p. 334). Por mais declarado e garantido nos nossos principais diplomas, que é Direito e Garantia Fundamental, os danos podem ser gerados. Na perspectiva de Norberto Bobbio:

Todas as declarações recentes dos direitos do homem compreendem, além dos direitos individuais tradicionais, que consistem em liberdades, também chamados direitos sociais, que constituem em poderes (...) São antinômicos no sentido de que o desenvolvimento deles não pode proceder paralelamente; as realizações integrais de uns impedem a realização integral de outros. Quanto mais aumenta os poderes dos indivíduos, tanto mais diminuem as liberdades dos mesmos indivíduos. (BOBBIO, 1992, p. 21) 


\section{Ainda Sidney Cesar S. Guerra:}

Direitos Fundamentais são aqueles direitos que, aplicados diretamente, gozam de uma proteção especial nas Constituições dos Estados de Direito e são provenientes de um amadurecimento da própria sociedade no que se refere à proteção destes direitos (GUERRA, 2001, p. 116).

Assim, resta evidente a necessidade de proteção a esse direito, pois individualiza a pessoa em si, na sociedade em que vive. De acordo com Zygmunt Bauman, trocamos o pesadelo parótico de "Nunca estar sozinho" pela esperança de "Nunca mais vou ficar sozinho”. (BAUMAN, 2013, p. 30)

O Direito à Intimidade é superior a qualquer da vontade humana, esta intransponível, acima de tudo imaginável. É algo antecedente natural da personalidade e da capacidade jurídica do ser humano. Como o Direito à intimidade é ligada aos direitos da personalidade, eles se definem como absolutos, indisponíveis, essenciais e inerentes à pessoa humana. Liliana Minardi Paesani menciona Rodotá quando afirma: "Nós somos os nossos genes, nós somos nossos dados". (PAESANI, 2013, p. 31).

Patrícia Peck Pinheiro cita Castells, onde ele indaga "aquele que decide se conectar aceita, mesmo que tacitamente, o resultado da socialização dos seus dados, ou melhor a perda do controle das suas informações" (PINHEIRO, 2016, p. 100). Assim, você paga um certo preço pro novo mundo digital, você não paga com valores as mídias sociais, mas usa e o pagamento que não é em valores reais, são coletando as informações pessoais de cada um que aceita ter os aplicativos. Ao dar o aceite, aceitamos os termos do uso. Nesta hora são repassadas as informações pessoais para essas empresas. Para Patrícia Peck Pinheiro:

Hoje a maior parte dos termos de uso destes serviços deixa muito claro que, por mais que a pessoa deixe de ser usuária, o que ela compartilhou por ali fica lá na galáxia da Internet para sempre, e cabe apenas a ela a responsabilidade de refletir antes sobre qual legado de conteúdo quer deixar a seu respeito, já que tecnicamente ainda é bem difícil conseguir praticar o direito ao esquecimento (PINHEIRO, 2016, p. 101).

Ainda, não vivemos na Era da liberdade de expressão. Então, nessa hora que entra o ordenamento jurídico para equilibrar a relação entre os mais fracos com os mais fortes. Trazendo segurança jurídica e civilidade. Desde o findo da $02^{\mathrm{a}}$ Guerra Mundial, as Leis foram elaboradas no intuito de proteger o indivíduo da própria coletividade, decorrente a isso, tivemos diversas Constituições Federais. O intuito de todas, proteger à intimidade, à 
reputação, à imagem, à liberdade, à proteção dos dados e comunicações, dentre outros direitos fundamentais.

Nas últimas duas décadas cresceu de forma exponencial a captação desses dados e, no Brasil, inexistem mecanismos efetivos para proteção dos parâmetros mínimos de privacidade dos usuários de tecnologias e aplicações de internet - não obstante a existência do Marco Civil da Internet (Lei 12.965/2014) e suas determinações normativas quanto à necessidade do livre esclarecimento e consentimento como requisito para a coleta, uso, armazenamento, tratamento e proteção de dados pessoais, não é isso que se observa em termos práticos (LIMA; BARRETO JUNIOR, p. 241). Yves Alexandre de Montjoye (2017, internet) afirma que o primeiro obstáculo na aplicação tecnológica dos algoritmos é garantir a privacidade dos indivíduos:

\begin{abstract}
Como os algoritmos têm acesso a dados provenientes de um número crescente de fontes, mesmo se esses dados são anônimos, a partir de seu cruzamento e combinação seria possível inferir algumas características sobre uma pessoa em particular, ainda que essa informação nunca tenha sido divulgada pelo indivíduo. Felizmente, medidas podem ser tomadas para minimizar ou eliminar o impacto sobre a privacidade, tais como a agregação de dados anônimos. O desenvolvimento de algoritmos para a tomada de decisões com base em dados reflete a busca da objetividade e da aspiração de decidir baseando-se em evidências de modo a eliminar - ou pelo menos minimizar - a discriminação, a corrupção, a injustiça ou a ineficiência das quais, infelizmente, as decisões humanas não escapam.
\end{abstract}

O direito à privacidade ou resguardo é um direito casuístico por natureza, que suscita uma proteção como critério orientador da imprensa livre, em uma sociedade democrática (DE LUCCA \& SIMAO FILHO, 2000, p. 476). Ainda, Rodotá esclarecia: "na onda das ferramentas digitais, as pessoas surfam muitas vezes inocentemente sem dar-se conta do informar” (ALMEIDA, TEIXEIRA, \& TEPEDINO, 2016, p. 354). Conforme leciona Patrícia Peck Pinheiro:

\footnotetext{
A segurança da informação sempre encontrou uma barreira natural na privacidade. Afinal, se a monitoração e a vigilância são essenciais para prevenção de incidentes na Sociedade Digital, como fica a questão da privacidade neste mundo tão vigiado? Há quem justifique o aumento da vigilância na Internet, que muitas vezes ultrapassa os limites da ética e da legitimidade e esbarra na espionagem digital (PINHEIRO, 2016, p. 481).
}

A espionagem internacional digital e a violação da privacidade dos usuários da internet são um problema mundial, pois ainda inexiste uma instituição que determine os limites em que os Governos, empresas e serviços de segurança, possam adentrar. Para algumas pessoas, durante a navegação na internet, nas mídias sociais, estes usuários ficam em 
um processo de imersão, como se estivesse em um sonho. Com isso, acabam expressando desejos que na vida pessoal pensaria muitas vezes antes de demonstrar. Muitos deles se expõe demais na internet, alguns, sem imaginar os riscos que correm, outros, até sabem, mas por se sentir "feliz" assume o risco. Mas é possível observar, que a maioria aprendeu a se relacionar com o mundo de forma virtual. A intenção delas, não é buscar a problematização de sua vida, o autoconhecimento, mas a confirmação de suas convicções e ser objeto do olhar alheio.

Falar de si próprio para um grupo exagerado de amigos virtuais, gera um prazer equivalente ao de se alimentar, ganhar dinheiro, dormir ou se relacionar sexualmente. "Em uma conversa formal, as pessoas falam de si cerca de $30 \%$ do tempo, enquanto nas redes sociais este índice sobe para 90\%, com possibilidade de um feedback imediato. Isso gera inconscientemente uma sensação de prazer instantâneo, mas não sustentável.

A vida virtual é diferente da real. Nas redes sociais não importa quem você é e o que faz, mas o que representa para o mundo com suas postagens. Por isso, quem se expõe em excesso não leva em conta o quanto isso pode lhe prejudicar mais do que quem não age dessa forma. Essas pessoas acham que as consequências serão para todos, mas, na verdade, serão proporcionais à sua exposição.

\section{Hiperexposição vs. Segurança}

Com a criação do Youtube, no ano de 2005, foi permitido aos usuários comum a capacidade de publicar e visualizar, facilmente, vídeos na internet, sem que se necessitasse conexão direta entre as partes. Essas conexões eram feitas através de computadores de mesa, pois nessa época, as tentativas dessa tecnologia por aparelhos moveis, eram frustrantes pelo péssimo sinal da telefonia na época. Então, no ano de 2007, Steve Jobs apresenta ao mundo da telefonia, a maior revolução, o lançamento do primeiro IPhone.

A grande parte da população mundial não imaginava que estavam prestes a passar por uma migração tecnológica. Pois parte das atividades que antes era possível apenas por computadores de mesa, passariam a ser feitos através dos Smartphones, em especial, com a evolução do sistema Androide que é produzido pela Google e o IOS que é produzido pela Apple. 
Passamos a vivenciar a explosão de aplicativos, criados por plataformas, sendo criado redes sociais, conectando usuários, transferindo informações. Esclarece Lima "de nada adianta formidáveis softwares antivírus instalados e firewalls bem configurados se aquele que utiliza a rede clica em qualquer aplicativo sugerido ou informa dados sensíveis, sem se certificar do local onde se encontra" (LIMA, 2016, p. 73).

As mídias sociais são capazes de fornecer um grande apanhado de informações sobre seus usuários, esses dados, podem ser usados e utilizados para inúmeras funções. Ainda segundo Lima:

Um recrutador de uma empresa pode verificar os costumes de um candidato, um pretendente amoroso pode tentar descobrir mais sobre seu provável parceiros ou um criminoso pode coletar informações valiosas de suas próximas vítimas. Nesse último caso, é preocupante a forma como grande parte dos usuários se portam, deixando escancarado um arsenal de informações para os criativos estelionatários, pois, numa simples visita a um perfil, é possível descobrir nome de parentes (inclusive de filhos), locais que a pessoa frequenta (por exemplo, nome da escola dos filhos) e outras valiosas informações capazes de montar engenhosos plenos de ataques (LIMA, 2016, p. 127).

Esse problema não é apenas as mídias sociais é comportamental. A Hiperexposição dos cidadãos nos últimos anos, agravou e muito. A grande parte da população mundial, se expõem nas mídias para demonstrar o que tem, onde estão, o que praticam, dentre muitas outras coisas. Isso tudo são espécies de capturas de informações, podendo gerar ataques via internet. Citado por Lima, cerca de 300 horas de vídeos são publicados no Youtube por minuto, tornando-o a maior rede de vídeos no mundo (LIMA, 2016, p. 129). Isto demonstra a hiperexposição dos cidadãos, e com tanta informação publicada, resta claro que não existe fiscalização atestando a possibilidade de publicação dos vídeos ou não. Ainda segundo o mesmo autor:

A existência do serviço de previa visualização e avaliação resultaria na impossibilidade econômica de existência do serviço, sem falar nas incontáveis dificuldades para lidar em escala mundiais com peculiaridades como, por exemplo, identificar se determinado conteúdo é considerado ilícito em determinado país. No caso do direito brasileiro, por exemplo, se trataria caso de censura prévia, ação proibida pela Carta Magna (LIMA, 2016, p. 130).

Ficamos divididos entre a exposição excessiva, liberdade de nos expressar, abrindo mão da segurança. Abrimos mão da segurança em prol da liberdade, trocamos a segurança, para atingirmos um ápice fictício de liberdade e exposição. Pois a liberdade de expressão, 
associada aos riscos relativos à diminuição da privacidade nos ambientes digitais, pode nos levar a uma situação de hiperexposição, que pode trazer também riscos pessoais presentes ou futuros, tanto da segurança quanto de reputação (GABRIEL, 2018, p. 69). Ainda a autora traz a informação:

Em 2010, o Facebook disponibilizou a funcionalidade de $c h e c k-i n$, para permitir que seus usuários compartilhassem suas informações de localização na rede social. Um mês após o lançamento dessa funcionalidade, uma rede de assaltantes nos Estados Unidos roubou equivalente a US\$ 100 mil em bens de 50 casas, mirando nas pessoas que faziam check-in em lugares longe de suas residências (GABRIEL, 2018, p. 69).

Frisa-se que conscientemente ou não, informamos nossas informações, nossas e de terceiros que conosco estão. O mundo sempre ofereceu diversos riscos, quanto oportunidades, na rede acontece o mesmo, acessando as mídias sociais de forma ingênua, sem se importar com sua hiperexposição. Muitos acabam tendo sua reputação atingida, a única forma de controlar a reputação é por meio da privacidade, que permite que uma pessoa revele seletivamente os aspectos sobre si que construam sua imagem.

Quando as pessoas param de exercer esse controle sobre sua privacidade e os tipos de informações pessoais que revelam on-line, elas podem estar comprometendo a sua reputação, pois ela vai para a internet, lá permanece virtualmente para sempre (GABRIEL, 2018, p. 72). Todos os nossos comentários, curtidas, bate papo, fotos, check-in, fazem partes da construção da nossa reputação. E ele se divide em:

Pegadas (footprint) - são informações pessoais que compartilhamos ativa ou intencionalmente na internet, como que publicamos em posts e comentários nas mídias sociais, check-ins, fotos e etc.

Rastros (traces) - são informações pessoais que compartilhamos passiva ou inconscientemente na internet, como os dados que disponibilizamos quando navegamos pela rede, como o nosso IP, localização. Configuração do computador e browser que usamos, IMEI do nosso telefone celular, hábitos de e-mail, preferencias por diferentes assuntos ou coisas na internet.

Sombras (Shadows) - são as informações sobre nós que são compartilhadas por terceiros: fotos menções, depoimentos, opiniões e etc. (GABRIEL, 2018, p. 74).

Somos responsáveis pelas nossas ações e conteúdos compartilhados, pesquisados, nas mídias sociais e quando estamos on-line ou off-line deixamos nossos rastros digitais denominados de "sombras". Ao permitir e iniciar os testes de brincadeira na internet para determinar com qual personagem você se parece em um filme, você está dando informações sobre os seus traços de personalidade (GABRIEL, 2018, p. 76). A maior preocupação disso 
tudo é que ao mesmo tempo em que pode ser manipulativo, dificilmente pode ser detectado, excluindo a privacidade na internet.

\begin{abstract}
A soma dos nossos rastros com nossas pegadas constitui um dossiê riquíssimo sobre nós que permite que os sistemas computacionais determinem nossa personalidade, de forma muito mais precisa do que um humano conseguiria fazer: preferencias, reações, comportamentos específicos, fobias etc. Acredito que mesmo que consigamos exercer a nossa privacidade para construir nossa imagem, ou até mesmo, "fingir" para humanos, o cenário digital atual tem tornado muito mais difícil de fazermos o mesmo quando se trata de computadores - para esses, estamos ficando cada vez mais transparentes, em nossa totalidade, quer queiramos ou não. Nesse sentido, o nosso poder de exercer privacidade está cada vez mais comprometido, conforme a tecnologia computacional inteligente avança e evoluem e isso, talvez, requeira que pensemos e reestruturemos nossas relações sociais (GABRIEL, 2018, p. 77).
\end{abstract}

Quando mais ficamos conectados por meio das mídias sociais e do uso das tecnologias e sensores da Internet das Coisas, mais ainda oferecemos nossos dados pessoais, colocando em maiores riscos a nossa segurança, pois para termos acesso a essas tecnologias, passamos nossos dados sensíveis. A hiperexposição está atrelada ao uso compulsivo das mídias sociais, expondo a vida cotidiana, sem ter ideia dos riscos que podem causar, muitos ainda, sequer se preocupam com a segurança da rede. Inicia-se o uso por um habito de informar e acaba por um vício em se expor.

Entre as tecnologias digitais que alavancam hábitos descritos anteriormente informação em tempo real, exposição e conexão, uso da tecnologia e multitasking, o smartphone é a principal, pois converge com todas essas atividades para um único dispositivo, que, ao mesmo tempo, tende a estar sempre ao nosso alcance. Após a tempestade Sandy em 2012, em Nova Iorque, que provocou a falta de energia elétrica, diversos nova-iorquinos reportaram que sofreram crise de abstinência de celular (GABRIEL, 2018, p. 87).

Destarte para demonstrar o vício da exposição. Após acontecimentos terríveis com a natureza, as preocupações de vários cidadãos eram com a falta de energia elétrica para carregar os smartphones e não com a sua própria segurança. Hoje em dia, a medidas em que a tecnologia digital permite, conexão e exposição, as pessoas tem se exposto cada vez mais e passam cada vez mais tempo conectadas. Estranhamente, passam mais tempo conectadas e cada vez mais estão sozinhas.

O que tem nos validado e nos tornado reais para nós mesmos é sermos vistos por outros. Temos testemunhado esse fenômeno se intensificar conforme as pessoas ficam mais conectadas e com smartphones melhores, com câmeras melhores, tanto que a palavra selfie foi eleita a palavra de 2013 pelo Oxford Dictionaries. As estatísticas mostram que acidentes com selfies têm matado mais do que tubarões. Registrar e compartilhar registos sobre a vida tem se tornado mais importante do que viver (GABRIEL, 2018, p. 91). 
Muitos cidadãos troca viver e registrar a vida por somente registrar para expor. $\mathrm{O}$ primeiro é extremamente importante para o bem-estar da felicidade do momento, acontece que a exposição do segundo, é apenas para alimentar o ego.

\begin{abstract}
A adolescência é um estágio crítico do desenvolvimento, um período em que o cérebro avança do pensamento concreto para o abstrato. É quanto tradicionalmente os adolescentes desenvolvem sua capacidade para compreender a experiência emocional dos outros, bem como aprender e praticar suas habilidades de empatia. No entanto, horas de exposição por dia a telas de computador e vídeo, ouvindo música alta ao mesmo tempo, impede o desenvolvimento dos circuitos cerebrais adequados necessários para completar esse estágio. Infelizmente, a obsessão por tecnologias computacionais e videogames parecem estar atrofiando o desenvolvimento do lobo frontal em muitos adolescentes, prejudicando suas habilidades sociais de raciocínio. Além de afetar nossas funções cerebrais e habilidades sociais, o excesso de tecnologia pode também nos intoxicar e afetar nossa percepção e atuação no mundo. Vivemos cada vez mais imersos em tecnologia e, sem que percebamos, ela nos intoxica. Essa intoxicação tecnológica causa principalmente uma sensação de ausência de significado em nossas vidas e, em função disso, buscamos cada vez mais a nossa humanidade para combater esse vazio (GABRIEL, 2018, p. 98)
\end{abstract}

Muitos cidadãos expõem fatos importantes da vida cotidiana, vivem conectados o tempo inteiro, vivem cercados de tecnologias, mas sentem-se sozinhos e sentem falta do toque humano. Se expõem nas mídias para alimentar um ego, correm riscos, mas ao fim, perdem a segurança, correm riscos da sofrerem com a reputação exposta e por fim, estão sozinhos, mesmo tendo dezenas e dezenas de amigos nas mídias sociais.

Acabam por si perdendo sua integridade, pois ao expor-se de forma excessiva acabando perdendo sua segurança. A perda da integridade se dá quando, inexistindo a devida segurança, ocorre a modificação de um tópico importante, que pode ser alterado pelos mais superintendentes motivos, até mesmo intencionalmente (DE LUCCA \& SIMAO FILHO, 2000, p. 133).

A confidencialidade é a segurança na rede é o sigilo das informações que informamos a terceiros. Se algumas informações forem vistas e copiadas por algum indivíduo que esteja usando a internet para praticas do mal, o ponto segurança não está sendo observado. A sociedade da informação atualmente busca um equilíbrio entre a prestação da notícia e a reserva da vida privada (DE LUCCA \& SIMAO FILHO, 2000, p. 469). O que acontece que muitas pessoas a deixam abertas para se fazerem notáveis na rede. Se expõem para se sentirem bem, melhor. 
Atualmente as exposições nas redes sociais passaram a acontecer de forma desenfreada, como: fotos, vídeos caseiros com conteúdo sensuais, comentários e xingamentos. O modo de diversão das usuários estão sendo alterado, todo o material coletado por vídeos e fotos são publicadas instantaneamente nas redes sociais. A privacidade desses usuários que se expõem de maneira exagerada nas mídias sociais não é mais prioridade, uma vez que detalhes de suas vidas são postados, podendo comprometer as relações sociais e profissionais. Curioso, mas muitas empresas hoje em dia, antes de contratarem um colaborador "investiga" o perfil do candidato nas mídias sociais. Outras, que já trabalham, mas se ausentam dos seus empregos com falsas justificativas e, ao mesmo tempo, demonstram outra realidade nas redes sociais, participando de eventos sociais nos horários de trabalho.

De acordo com estudos recentes, as crianças nascidas entre 1998 e 2002, conhecidas como a Geração Z, tendem a sofrer mais ainda com a dependência de hiperexposição decorrente ao uso exagerado dos seus smartphones no seu dia a dia. Essas crianças, tratam os smartphones como "melhores amigos". Esta pesquisa buscava melhorias nos seus aparelhos, dando melhores condições para os usuários falarem, interagirem, fotografarem com seus amigos que estavam em cidades, países distantes, mas pediam ainda aos usuários, que não esquecessem dos amigos que estavam próximo. Acontece que a finalidade da pesquisa acabou demonstrando que hoje em dia, a dependência pelo uso dos smartphones está cada vez maior. Mas a busca de muitos, não é interação e sim se expor para demonstrar o que pode ser e o que possa ter. trata-se de um alimento ao Ego.

A hiperexposição gera danos irreversíveis aos usuários, e na maioria das vezes, eles não: se importam em se expor, ou não tem a menor ideia do risco que correm. Abrem mão da segurança, para se sentir bem na exposição virtual. O velho ditado antigo dito pelos nossos avos, nunca fizeram tanto sucesso nos dias atuais: a nossa vida está sendo um livro aberto!

\section{CONSIDERAÇÕES FINAIS}

O Direito não é ciência exata. Esse ambiente denominado Internet, multiplicam-se interações humanas em conjunto com uma serie de ferramentas. Esses resultados, nem sempre são benéficos para a sociedade. De qualquer forma, todas as mudanças bruscas estão sendo assimilada pelo ordenamento jurídico. Pois é inegável a evolução que passou a ter o direito 
digital no judiciário brasileiro. Ainda, há uma legislação, em determinados pontos, alheias às tecnologias, no caso desse presente trabalho, a hiperexposição por vezes inocentemente, acabam permitindo que terceiros de má-fé usam os dados sensíveis desses cidadãos para usos totalmente indevidos.

Afirma-se que a Internet foi uma das mais importantes invenções da história da humanidade. Um evento encadeado que mudou definitivamente os rumos de nossa sociedade que, como rede global, não permite que o Estado brasileiro estipule regras especificas (LIMA, 2016, p. 304). É de extrema importância a Internet nas nossas vidas e mais importante ainda compreender que existirão obstáculos inseridos na história da criação da rede, pois por ela, atingimos alcance mundial. Ao expormos fatos, versões, fotos, opiniões, dentre outros, podemos nos deparar com terceiros maldosos, que estão ali para praticar o mal na rede, usando a inocência das pessoas para praticar o mal.

Se existem seres humanos capazes de utilizar a ferramenta para gerar desgraça, devem ser eles os combatidos, jamais a rede. Essa Internet que tanto amamos precisa ser cuidada, pois ela é patrimônio de todos nós (LIMA, 2016, p. 305).

A internet é essencial em nossas vidas. As redes sociais são grandes aliadas, quando utilizadas para informação, mobilização, ajuda, notícias, acontecimentos. Mas com relação à exposição pessoal está cada vez pior. As pessoas que tem a tendência a hiperexposição delas mesmas, levam junto a exposição dos dados de seus amigos, seguidores, e seguidores de seus amigos, toda uma rede de contatos. Conectando todos com informações que por vezes são inúteis, mas todos os conectados têm acesso.

\section{REFERÊNCIAS}

ALMEIDA, Vitor; TEIXEIRA, Ana Carolina Brochado; TEPEDINO, Gustavo (coords.). $O$ Direito Civil entre o sujeito e a pessoa: estudos em homenagem ao professor Stefano Rodotá. Belo Horizonte: fórum, 2016.

ASCENSÃO, José de Oliveira. Direito da Internet e da sociedade da informação. Rio de Janeiro: Forense, 2002.

ASCENSÃO, José de Oliveira; CORDEIRO, Pedro; VON LEWINSKY, Silke; DA MOTA, José Lopes; UIDE, Carlos; VITORINO, António Macedo. Sociedade da Informação: estudos jurídicos. Coimbra: Almedina, 1999.

BARBOSA, Marco Antônio. Poder na Sociedade da Informação. In: PAESANI, Liliana Minardi (Coord.). Direito na Sociedade da Informação. São Paulo: Atlas, 2007.

BARRETO JUNIOR, Irineu Francisco; VENTURI JÚNIOR, Gustavo. Dados pessoais na 
internet: análise do seu status enquanto mercadoria na sociedade da informação. Anais do $41^{\circ}$. Encontro Anual da ANPOCS. Disponível em: http://www.anpocs.com/index.php/papers-40encontro-2/gt-30/gt02-25/10599-dados-pessoais-na-internet-analise-do-seu-status-enquantomercadoria-na-sociedade-da-informacao/file> Acesso em 10.nov. 2107.

BARRETO JUNIOR, Irineu Francisco. Proteção da Privacidade e de Dados Pessoais na Internet: O Marco Civil da rede examinado com fundamento nas teorias de Zygmunt Bauman e Manuel Castells. In: DE LUCCA, Newton; SIMÃO FILHO, Adalberto; DE LIMA; Cintia Rosa Pereira. (Org.). Direito \& Internet III. São Paulo: Quartier Latin, 2015. p. 100-127.

BAUMAN, Zygmunt. Vigilância líquida: diálogos com David Lyon/Zygmunt Bauman. Rio de Janeiro, RJ: Zahar, 2013.

BOBBIO, Norberto, A Era dos Direitos. Rio de Janeiro: Campus, 1992.

DE LUCCA, Newton; SIMÃO FILHO, Adalberto (coords.). Direito e Internet: aspectos jurídicos relevantes. Bauru, SP: Édipro, 2000.

GABRIEL, Martha. Você, eu e os robôs: pequeno manual do mundo digital. São Paulo: Atlas, 2018.

GUERRA, Sidney Cesar Silva. SILVA JUNIOR, da Roberto Roland Rodrigues (coord). Internet e Direito Reflexões Doutrinárias. Rio de Janeiro: Lumen Juris, 2001.

GUSTIN, Miracy B.S.; DIAS, Maria Teresa Fonseca. (Re)pensando a pesquisa jurídica. 2.ed. ver., ampl. e atual. Belo Horizonte: Del Rey, 2006.

LIMA, Glaydson de Farias. Manual de Direito Digital: fundamentos, legislação e jurisprudência. 1.ed. - Curitiba: Appris, 2016.

LIMA, Marco Antônio. BARRETO JUNIOR, Irineu Francisco. Marco Civil da Internet: limites da previsão legal de consentimento expresso e inequívoco como proteção jurídica dos dados pessoais na internet. Revista de Direito, Governança e Novas Tecnologias. Brasília v. $1 \mid$ n. $2 \mid$ p. $241-260$ Jan/Jun. 2016.

MONTJOYE, Yves Alexandre de. Big Data': antídoto contra a corrupção? Disponível em: <https://brasil.elpais.com/brasil/2017/03/24/ciencia/1490358953_071638.html>. Acesso em: 27. Mar. 2017.

PAESANI, Liliana Minardi. O Direito na Sociedade da Informação II. São Paulo: Atlas, 2009. O Direito na Sociedade da Informação III. A evolução do Direito Digital.

São Paulo: Atlas, 2013.

PINHEIRO, Patrícia Peck. Direito digital. 6. ed. São Paulo: Saraiva, 2016.

RODOTÀ, Stefano. A vida na sociedade da vigilância - a privacidade hoje. Tradução Danilo Doneda e Luciana Cabral Doneda, Rio de Janeiro: Renovar, 2008.

SCARZELLI, Patrícia. A Comunidade Cibernética e o Direito. Rio de Janeiro: Lumen Juris, 1997.

\section{Documentos Eletrônicos}

https://www.significados.com.br/world-wide-web/ 
http://g1.globo.com/sao-paulo/itapetininga-regiao/noticia/2015/06/serie-invasao-deprivacidade-aborda-exposicao-pela-internet-e-rede-social.html

https://www.techtudo.com.br/noticias/2018/03/dependencia-por-smartphone-gera-panico-em56-dos-brasileiros-diz-pesquisa.ghtml

https://www.universal.org/noticias/quando-a-exposicao-na-internet-passa-do-limite 